\title{
Teaching with Compassion:
}

\section{Autoethnographies from the front lines of e-learning}

\author{
${\text { Linda } \text { Carozza }^{1(\bowtie)} \text { and Steve Gennaro }}^{2,3}$ \\ ${ }^{1}$ Department of Philosophy, York University, Canada \\ ${ }^{2}$ Department of Humanities, York University, Canada \\ ${ }^{3}$ Instructional Designer, Faculty of Liberal Arts \& Professional Studies, York University, Canada \\ Lcarozza@yorku.ca
}

\section{ABSTRACT}

In 2020 the landscape of teaching in higher education was forced to change given a global pandemic. As a result there were/are inevitable shifts in how course instructors develop and deliver their courses, as well as how they connect with students. Remote, or distance, learning is not a new phenomenon, and elearning has been delivered across different institutions of higher education for approximately twenty years. However, scholarship in distance learning is dated and the empirical literature in digital pedagogy has gaps when it comes to best practices for teaching and learning in an online format. This paper highlights the importance of teaching with compassion as it fosters better relationships between instructors and students and helps to build community in learning environments. Relationships facilitate learning, and this is especially important in strained times - such as a higher concentration of online teaching and learning due to a pandemic. The notion of compassionate teaching is described. Using self ethnography and drawing on examples from their own course experiences, the authors present what has worked well in delivering small and large courses online. In particular, the first half of the paper focuses on backward course design, multimedia, accessibility, and forward/backward extensions. The latter half of the paper describes strategies embedded in a course and their positive effects for instructors and learners.

Keywords: community of learning, compassion, digital pedagogy, engagement, teacher presence

Cite this article as: Carozza, L., \& Gennaro, S. (2021). Teaching with Compassion: Autoethnographies from the front lines of e-learning. Journal of e-learning Research, 1(1), 1-10. https://doi.org/10.33422/jelr.v1i1.49

\section{Introduction}

In 2020 the landscape of teaching in higher education was forced to change given a global pandemic. As a result, there were/are inevitable shifts in how course instructors develop and deliver their courses, as well as how they connect with students. Remote, or distance, learning is not a new phenomenon, and e-learning has been delivered across different institutions of higher education for approximately twenty years. However, scholarship in distance learning is dated, given evolving web technologies, and the empirical literature in digital pedagogy has gaps when it comes to best practices for teaching and learning in an online format. Using selfethnography and drawing on examples from their own classroom experiences, this paper reviews best practices for digital teaching and learning, both synchronously and asynchronously, for the current learning environment and for the post-COVID-19 university classroom. More specifically, this paper summarizes 1) what has worked well in delivering 
small and large courses online; 2) what specific online tools have proven invaluable for instructors; and 3) what additional skill sets are important from the perspective of instructors and learners. Ultimately, we conclude that what is required for successful online learning environments is community. This paper highlights the importance of teaching with compassion as it fosters better relationships between instructors and students and helps to build real community in online learning environments. Relationships facilitate learning and this is especially important in the time of COVID-19.

\section{Methodology}

This article is an autoethnographic exploration of digital pedagogy. As stated by Ellis, Adams, and Bochner (2010), "When researchers do autoethnography, they retrospectively and selectively write about epiphanies that stem from, or are made possible by, being part of a culture and/or by possessing a particular cultural identity. However, in addition to telling about experiences, autoethnographers often are required by social science publishing conventions to analyze these experiences (p. 276)." In this article, we discuss our online teaching experiences with particular attention paid to the ingredients that foster online communities of learning within higher education courses. In addition to being online instructors (pre-COVID-19 and during the COVID-19 pandemic), we have also assumed roles within our home University faculty training, consulting with, and supporting other faculty members on incorporating best practices for digital teaching and learning. As a result, what emerges in the following discussions of teaching with compassion in small scale courses and highlighting enhanced communication mechanisms in large scale courses are part experiential: based on our own experiences of teaching and reflections on those experiences, and part anecdotal: based on our discussions of teaching and learning with other faculty regarding their experiences. This represents both the richness and the limitations of autoethnography as research methodology.

\section{Results and Discussion}

\subsection{Small Scale Courses: The Importance of Teaching with Compassion}

Teaching inside the smaller classroom online possesses some unique challenges for instructors in higher education. For example, one of the questions I heard most often in the spring and summer months when working with instructors leading tutorials of 20-30 students - upperlevel seminar classes of similar numbers or smaller, and those teaching graduate seminar classes - was "how do I recreate the conversation and group dynamic of the classroom online?" This is not a new question, nor is it a question that is unique to responses to COVD-19. Questions surrounding the creation of community in teaching small scale classes in virtual classrooms have been at the forefront of research dating as far back as Knupfer, Gram, and Larsen (1997). We are building a community with our students; we create a relationship with our students in the online learning environment where we provide them the opportunity to succeed. Students need to feel that they are part of a community to succeed online. Winograd (2000) noted the success of creating online communities of learners are determined by the elements of camaraderie, support, and warmth. Two decades later, and now more deeply entrenched in virtual learning spaces, the early research still holds true. Ultimately, the desire 
here is to replicate "the human" in a space that is predicated on the removal of the human by its very existence!

Rather than trying to paper-mâché a solution to this overarching question of teaching the small class online, my approach at York University, whether synchronous or asynchronous, has been to suggest that faculty practice teaching with compassion. To teach with compassion is:

1) to design a course where the learning environment is built to be inclusive to all students; 2 ) to structure a course where modes of assessment provide all students multiple opportunities to achieve success; and 3) to teach a course with a genuine feeling of concern for others.

To teach with compassion then requires a commitment to universal design for learning (UDL). York University's Teaching Commons (n.d.) “address[es] issues of accessibility, inclusivity, diversity, and academic honesty pre-emptively and at the level of course structures and components" (para. 1). More recently, researchers like Hromalik et al. (2019), drawing on the work of Myer et al. (2014), have noted successful professional development for faculty in UDL principles, some of which include: multiple means of engagement, multiple means of representation, and multiple means of expression that can "lead to a change in classroom practice, which affects student learning outcomes" by promoting better learning environments for higher education students (pp. 91-92). Teaching with compassion fosters better relationships with our students and helps to build community in our learning environments. What we have always known to be true in the traditional classroom, has now been corroborated by recent research on online teaching and learning; relationships facilitate learning (Adams, 2020; Dilling, 2020; Ouyang, 2020). And this is particularly important in the time of COVID19.

From my experiences teaching online (both successful and unsuccessful) here are some strategies I have found to be very helpful for teaching smaller classes. The first task of teaching with compassion requires a clarity of objectives and expectations. In order to achieve this clarity, we must spend time organizing off-line as much as possible what you want to accomplish in your online course before the course begins and you go online. This means knowing what your learning objectives are and how you plan to evaluate those objectives (see Carr-Chellman \& Duchastel, 2000). For those familiar with backward-course design (Wiggins $\&$ McTighe, 2005), this is a pedagogical method that enhances the online learning experience - particularly because it forces instructors to build a course that clearly and succinctly informs students of the purposes of course activities (Darby \& Lang, 2019, pp. 7 -10). Virtual learning spaces can be difficult to navigate and when a student feels confused about the layout of the course, or where to find something in the course, they do not feel like part of the community. Some students will ask for help in a forum, or email a professor, or ask a fellow student. But many will not. They will start the process of pulling away from the course. And our task as educators is to connect our students as many ways as possible to the course, to the content, and to the community. The more clear, clean, precise, and accessible the course objectives, assignments, activities, and outcomes are - the more likely to engage and succeed are students are too!

The second task of teaching with compassion is to use video everywhere and as much as possible. Now before going any further, let me state with extreme importance - that all video needs to be accompanied by a text transcript for your students to ensure accessibility. Not only is this required to comply with universal design for learning (UDL) principles, but in the 
Province of Ontario where I teach, the 2005 Accessibility for Ontarians with Disabilities Act tells us that UDL is actually the law (Meilleur \& Ontario, 2006). Some platforms, like Zoom, allow you to record a video message or lecture for students with the option of adding an automatic transcript and closed captions (CC) - or the option to record video messages or mini lectures on your cell phone and upload them to a YouTube channel could also work - since YouTube also provides CC technology. But what I have noticed in my own teaching, is that no single action has had a more profound impact on the creation of community and student engagement than the increase of video messaging from me to my students. This is particularly true for my asynchronous teaching, but it also has proven to be a valuable addition to synchronous teaching delivery as well. This takes two forms: first, each week I send a video message by email to all my students to check in, say hello, and offer some tips for the week. And second, every piece of text I post to my learning platform for students to read or download - I accompany with a video of me reading or explaining. In some of my courses, I have even gone one step further to have my students use video responses instead of forum posts or essays - as their primary way of communicating with other students (asynchronously) or for classroom assessment (Gennaro, 2018).

Third, it is important to think about differentiated learning. At York University, differentiated learning is often referred to as accessible education, which "is the process of designing courses and developing a teaching style to meet the needs of people from a variety of backgrounds, abilities and learning styles" (Teaching Commons, 2012). Westbroek (2020) refers to accessible education as differentiated instruction, noting how "[one] approach is to let students work on common, complex 'whole' tasks with common goals, but to tailor support - learning routes - for finishing the tasks to the students' needs. What students 'need' varies ... [i]deally, support should be offered to each student at the exact level that enables him or her to complete the task" (p. 957). While differentiated learning is a concept that is often very foreign to us in higher education, it is a process or series of processes more familiar to high school and grade school educators where streaming of students, courses, and pathways takes place. For example, in high schools in the Province of Ontario, Canada where I live, students often select courses that are streamed to be "university" or "college" focused. Whereas, in Canberra, Australia where I lived previously, students and courses were not streamed, and teachers were encouraged to participate in differentiated instruction. Here, it is the teacher's responsibility to recognize different learners at different stages in their learning and with different learning styles and different learning practices inside each of their classrooms. By practicing differentiated instruction, the teacher delivers the same content to multiple tiers (for lack of a better word) of students. This is what we need to do to be successful in the online learning environment: there needs to be a basic level that you provide that is accessible to all students. However, there also needs to be differentiated paths to learning that include extensions in both directions: backward and forward. Extensions backward provide students with links to YouTube videos, podcasts, books, articles, and other resources so that students who require more knowledge on the subject in order to be successful in grasping where we are can catch up and not feel isolated or left out from our discussions and learning community. Extensions forward provide students who want more and feel limited and restricted (and therefore isolated and disconnected from the learning community) precisely because they are too engaged with the course material. In the past I have used many different strategies for forward extensions, 
including asking the student to give a guest lecture in the course. But here is the big point - by providing extensions in two directions we are creating lifelines to all our students. We are not teaching "to the middle." We are demonstrating to all of our students a compassion and desire to see them succeed. We are inviting all of our students, regardless of circumstance, to be active participants in our learning community.

When the community of learners is smaller, there are less places for our students to hide or to go unnoticed. Therefore, students who feel connected to the class or community will want to participate and will regularly engage. However, on the flip side, what occurs with students who do not understand what is going on? Or how the course is organized? Or what the purpose of activities or tasks are? Or those who struggle with the content, or who do not feel challenged by the content, and those who have difficulty accessing the content? In all these scenarios, the students will pull away from the learning community and engagement and connection will decrease. To teach a small-scale class online with the connection and energy of the traditional classroom on campus, requires more than just the energy of the instructor. It requires a coordinated effort from the instructor to design and implement a course that says all are welcome - both in form and in function. By teaching with compassion, we connect to our students, we build relationships and community, and provide all students with the best possible chances to succeed.

\subsection{Large Scale Courses: The Importance of Increased Communication}

A challenge encountered when teaching large online courses is student engagement. As instructors, we interpret a lack of engagement from learners in various ways: inability to adhere to deadlines; not reviewing course material (e.g., video lectures); higher attrition rates than in a face-to-face course; black squares with no voice/agency throughout synchronous sessions; and even students who submit assignments, but at the last possible minute. Some of these criteria are based on instructor perception and others can be corroborated by reviewing statistics related to learners' activity levels within the learning management system (Dennen, Darabi, \& Smith, 2007; Dixson, 2010, 2015). Perceived and/or explicit lack of engagement is likely related to student motivation. Students are motivated by different circumstances; for some students, the primary source of motivation is intrinsic, whereas for others the primary source of motivation occurs extrinsically (Vallerand et al., 1992, pp. 1005-1006). Students who are intrinsically motivated want to learn and demonstrate a genuine interest in the course. Intrinsically motivated students pose fewer challenges for instructors. What is more challenging for instructors are students who require extrinsic motivation to follow through with the course successfully. An example of extrinsic motivation is a final grade of A or passing a course. When building a course, these are the students we keep in mind. In part, we build courses to engage with students who require extrinsic motivation for engagement and success. When delivering the course, an increased level of communication between instructor and student, and between students themselves, can help serve as a strategy for extrinsically motivated students to stay connected to the course when traditional forms of engagement prove unsuccessful.

When designing courses, regardless of their method of delivery, we try to practice selfreflexivity and awareness, to ensure that we can continue to build stronger, more successful iterations of courses. What follows is a discussion of experiences in teaching and re-teaching a 
large online general education course, called Techniques of Persuasion, offered asynchronously over the last five years, and how it has been reorganized, leading to improvements in each course delivery. This course began with 50 students and a single instructor. Five years later, this course has an enrolment of 150 students and a teaching team. In particular, the focus here is on the improvements that were made to enhance the communication between instructor and students, and between students themselves.

Students often find teamwork projects challenging (Panitz \& Panitz, 1998, p. 167). Alleviating student concerns with collaborative learning activities is something that could be controlled and facilitated well in a face-to-face context, but becomes more challenging in an online learning environment. In the first online delivery of Techniques of Persuasion there were students who did not communicate with their team members, did not respond to emails, and who made the experience of working collaboratively stressful for other students. Perhaps, this was in part due to the nature of diverse students in general education courses, as students in this course can be from any level and any faculty/discipline, as all degrees have a breadth (general education) requirement. Some students voiced concerns (privately, via email) about a lack of engagement from their team members, and though this was a very small percentage of students who complained, this led to reflecting on the value of team projects in a large general education skills-building course.

In the subsequent iterations of Techniques of Persuasion, discussion forum participation was implemented to enhance student collaboration and communication. This involved a student making an initial post and responding to a peer's post within the span of a week. Typically, the outcomes of such posts, and responses to other students' posts, were related to skills of application, analysis, and evaluation - all higher-order cognitive levels according to Bloom's taxonomy (Bloom, 1956). Students were graded based on instructional criteria provided (i.e. a rubric as opposed to completion marks). While forums were embedded into course design to allow for collaboration yet function more successfully than team projects, for all students, issues still arose. I noticed a decrease of students who remained active on the forums for the duration of the course. In addition, when there was participation, it was occurring so late during the submission period that it left no time for other students to respond to their peers. And, it follows from this pattern that some students still expressed their concerns with relying on other students' participation in order to complete collaborative tasks.

As an instructor, I wanted a higher percentage of students to be present and active. I had already used grades as an extrinsic source of motivation. There were marks associated with team forum posts $-2 \%$ of the final grade was connected to a post of approximately 200 words. This is not insignificant - missing 3 weeks of forum posts bumps one down to a lower grade bracket. This, however, was not enough to encourage timely and full participation. My solution to this problem would not come for another 2 years, when I decided to alter the form and function of the forum activity by implementing singular discussion posts. With singular discussion posts, students were no longer required to respond to their classmates. For many students, this alleviated stress they felt and had voiced to me about depending on other students to submit work in a timely fashion (i.e. by the deadline). Students were still encouraged to read each other's posts, as they remained in teams and because they would not earn full marks if they repeated ideas of earlier teammates' posts. This continues to be how I embed participation tasks 
in this course; however, with enhancements related to communication mechanisms, there have been signs of increased student engagement as well.

In the summer of 2020, I was teaching this course to 150 students with a teaching team. My goals for improved delivery of the course were twofold: to minimize the busy-ness of the learning management system and to create an environment of engagement. Both were achieved. It was the most successful iteration of the course to date, and here are the facets of the course delivery that I believe were impactful with respect to student engagement.

1) Instructor introduction video (something that went well in 2019 as students responded with their own videos).

2) Embedding virtual boards for student input (e.g., share a course goal, favourite tv show binge, pet sharing photos, etc.). These were strategically embedded (i.e., not overused) into the course.

3) Regular course announcements (one to two weekly without fail) that reminded students to attend optional synchronous webinars (with the link) and provided a checklist of tasks to keep students on track.

4) A weekly tip related to learning or technology was inserted at the top of each week's learning material (12 weeks in a semester).

5) Optional synchronous sessions using Zoom. These functioned to practice skills application and/or as a live $\mathrm{Q} \& \mathrm{~A}$ opportunity.

6) Answers to the course Q \& A forum within 24 hours or less. All students see questions and answers. I had email alerts setup such that if a question was posed, I was alerted, and the answer was available soon after.

7) Responding to participation forum posts that students make. This was a radical shift from abstaining altogether from commenting on student posts within small teams, and it achieved teacher presence (Stone \& Springer, 2019; Carr-Chellman \& Duchastel, 2000).

8) Assignment deadline extensions that were not punitive (i.e., no "late" marks).

All these strategies collectively contributed to building relationships and community in an online course, and they are examples of teaching compassionately. For instance, extending assignment deadlines in an effort to acknowledge "life as we know it in 2020" cultivates care for students (Darby \& Lang, 2019, p. 104). In addition, strategically responding to some students' forum posts demonstrates our active participation and presence in a course. When we show up, so do our students.

Embedding these strategies singularly, over the different section deliveries of this course, was not entirely intentional initially. I had taught the course enough times to know the course was missing some magic, and I experimented with different strategies. In 2020 I made a wellplanned conscious decision to embed the 8 strategies listed above. The results surprised me. Two main - very noticeable - differences occurred: there was more uptake in the team forums for the duration of the course and students attended optional synchronous sessions (something they rarely made use of before) - both in formats of webinar and office appointments with me. Focusing on instructor presence and more frequent, varied, communication fostered an environment where i) more students were engaged with course material; ii) more students were making appointments with the instructor to ask questions and discuss their ideas/work; iii) there was a higher-class average; and iv) less enrolled students did not complete the course; and all in the height of a global pandemic. The latter three results are all measurable outcomes.

In a face-to-face course there are dynamics that create community within a classroom - casual conversations, environmental commonalities, and so on. Those natural connections are less 
obvious and available in a large asynchronous course. The embedded strategies of online course delivery listed achieve the criteria of compassionate teaching defined above. Consistent compassionate teaching measures can achieve a community of learning. Community is the heart of an engaging online course - for students and instructors both. Students who engaged in the course energized me, and it kept my presence as an instructor active, unwavering, and positive. In turn students were aware of instructor presence - via both the design and facilitation of the course (Darby \& Lang, 2019, p. 80). Community has to be purposefully built into an online course. It is not something we should hope will occur organically, and it begins at the level of course design (Carr-Chellman \& Duchastel, 2000).

\section{Conclusion}

While the global pandemic brought challenges to higher education - the most obvious one is that all instructors were forced to teach online for a (un)limited period of time - it also brought with it opportunities. Amid the scrambling to purchase supplies, the panic, pivotal Black Lives Matter protests, politicking for a presidential election, and debates about wearing masks, we found a budding community of instructors and staff in our university that shared ideas, taught each other skills, and offered each other (all kinds of) support. A group that had already been meeting in person monthly on campus - prior to the pandemic - built a stronger community meeting online after the pandemic was declared. This group continues to meet weekly as we write this article, and we are grateful for it.

We experience online communities in multiple spheres. What we have described, reported, and theorized in the context of our roles as - first and foremost - instructors in both small and large online courses for (combined) 20+ years, learning designer, e-learning mentor, and active members in an e-learning community of practice can be summarized by a causal pattern. Embedding compassionate teaching in an online course delivery facilitates relationship building. Relationships yield community. A community of learners in an online course helps to inspire student motivation. Motivated students yield student engagement. As an instructor we hope for engaged students. We hope that students walk away from a course learning new ideas and skills and feeling inspired along the way. This causal chain is also circular in motion. Engaged students, who feel a sense of purpose in their courses, strengthen an online course's community of learners. In closing we quote leaders in teaching and learning design: "Creating a sense of community in an online course involves both effort and intention ... [it] plays an essential role in the effectiveness of the course in producing learning" (Darby \& Lang, 2019, p. 77).

\section{References}

Adams, K. (2020). Research to Resource: Developing a Sense of Community in Online Learning Environments. Update: Applications of Research in Music Education. https://doi.org/10.1177/ $\underline{8755123320943985}$

Bari, M., Djouab, R., \& Hoa, C. P. (2018). Elearning current situation and emerging challenges. PEOPLE: International Journal of Social Sciences, 4(2). https://doi.org/10.20319/ pijss.2018.42.97109 
Bloom, B. S. (1956). Taxonomy of educational objectives handbook: Cognitive domain. New York: McKay.

Carr-Chellman, A., \& Duchastel, P. (2000). The ideal online course. British journal of educational technology, 31(3), 229-241.

Darby, F., \& Lang, J. M. (2019). Small teaching online: Applying learning science in online classes. John Wiley \& Sons.

Dennen, V.P., Darabi, A.A. and Smith, L.J. (2007). Instructor-learner interaction in online courses: The relative perceived importance of particular instructor actions on performance and satisfaction. Distance Education, 28(1), 65-79.

Dilling, V. (2020). Comparing Teaching and Social Presence in Traditional and Online Community College Learning Environments. Community College Journal of Research and Practice, 44(10-12), 854-869. https://doi.org/10.1080/10668926.2020.1752852

Dixson, M. D. (2010). Creating effective student engagement in online courses: What do students find engaging?. Journal of the Scholarship of Teaching and Learning, 1-13.

Dixson, M. D. (2015). Measuring student engagement in the online course: The Online Student Engagement scale (OSE). Online Learning, 19(4).

Ellis, C., Adams, T. E., \& Bochner, A. P. (2010). Autoethnography: An Overview [40 paragraphs]. Forum Qualitative Sozialforschung / Forum: Qualitative Social Research, 12(1), Art. 10, http://nbnresolving.de/urn:nbn:de:0114-fqs1101108

Gennaro, S. (2018, Dec. 5). Get Your Students Writing with YouTube [Conference Presentation]. Teaching in Focus Conference, York University, Toronto, ON, Canada.

Hromalik, M. (2019). “ALL Faculty Should Take this”: a Universal Design for Learning Training for Community College Faculty. TechTrends, 64(1), 91-104. https://doi.org/10.1007/s11528-01900439-6

Hubackova, S. (2015). History and perspectives of elearning. Procedia-Social and Behavioral Sciences, 191, 1187-1190.

Kellsey, D., \& Taylor, A. (2016). The Learning Wheel: A model of digital pedagogy. Critical Publishing.

Knupfer, N. N., Gram, T. E., \& Larsen, E. Z. (1997). Participant analysis of a multi-class, multi-state, on-line, discussion list. Proceedings of Selected Research and Development Presentations at the 1997 National Convention of the Association for Educational Communications and Technology, February 14-18, 1997 (pp. 133-139).

McTighe, J., \& Wiggins, G. (2005). Understanding by Design (2nd ed.). Alexandria, VA: Association for Supervision and Curriculum Development (ASCD).

Meilleur, M., \& Ontario. (2006). Accessibility for Ontarians with Disabilities Act, 2005 (AODA): 2006 annual report. Toronto: Ministry of Community and Social Services.

Meyer, A., Rose, D.H., \& Gordon, D. (2014). Universal design for learning: Theory and Practice. Wakefield, MA: CAST Professional Publishing.

Ouyang, C. (2020). Examining the instructor-student collaborative partnership in an online learning community course. Instructional Science, 48(2), 183-204. https://doi.org/10.1007/s11251-020$\underline{09507-4}$

Panitz, T., \& Panitz, P. (1998). Encouraging the use of collaborative learning in higher education. University teaching: International perspectives, 161-201.

Stone, C., \& Springer, M. (2019). Interactivity, connectedness and 'teacher-presence': Engaging and retaining students online. Australian Journal of Adult Learning, 59(2), 146. 
Taylor, A. (2017). Social work and digitalisation: Bridging the knowledge gaps. Social Work Education, 36(8), 869-879.

Vallerand, R. J., Pelletier, L. G., Blais, M. R., Briere, N. M., Senecal, C., \& Vallieres, E. F. (1992). The Academic Motivation Scale: A measure of intrinsic, extrinsic, and amotivation in education. Educational and psychological measurement, 52(4), 1003-1017.

Westbroek, v. (2020). A practical approach to assessment for learning and differentiated instruction. International Journal of Science Education, 42(6), 955-976. https://doi.org/10.1080/09500693. $\underline{2020.1744044}$

Winograd, D. (2000). The Effects of Trained Moderation in Online Asynchronous Distance Learning. In: Annual Proceedings of Selected Research and Development Papers Presented at the National Convention of the Association for Educational Communications and Technology (23rd, Denver, CO, October 25-28, 2000). Volumes 1-2; see IR 020712.

York University Teaching Commons. (2012, September). Introduction to Accessible Education Retrieved October 18, 2020, from https://teachingcommons.yorku.ca/wp-content/uploads/2015 /01/Introduction-to-Accessible-Education.pdf

York University Teaching Commons. (n.d.). Inclusive Design: Building Principles of Equity into Teaching and Learning. Retrieved October 18, 2020, from https://teachingcommons.yorku.ca/forcds/workshops-and-courses-for-cds/courses/inclusive-design-course/ 